\title{
Research on income influence of enterprise perishable under consumer strategy behaviour
}

\author{
Li Zhou ${ }^{1,}$, , Jing $\mathrm{Li}^{2}$, Dongsheng $\mathrm{Xu}^{2}$ \\ ${ }^{1}$ School of Information, Beijing Wuzi University, Beijing, China \\ ${ }^{2}$ Graduate department, Beijing Wuzi University, Beijing, China
}

\section{Email address:}

zhoulibit@126.com (Li Zhou)

\section{To cite this article:}

Li Zhou, Jing Li, Dongsheng Xu. Research on Income Influence of Enterprise Perishable under Consumer Strategy Behaviour. Science Journal of Applied Mathematics and Statistics. Vol. 2, No. 5, 2014, pp. 102-106. doi: 10.11648/j.sjams.20140205.13

\begin{abstract}
This paper studies the consumer strategy behavior impact on earnings of enterprises perishable products. It mainly considers the impact on the income from the income and cost analysis, and other factors how to influence the two factors, thus indirectly affect the retailer's cost. The conclusion of the study laid the theoretical foundation for the dynamic pricing for perishable products.
\end{abstract}

Keywords: Consumer Strategy, Perishable Goods, Revenue Management, Dynamic Pricing

\section{Introduction}

Perishable goods refers to the shorter life cycle of products, the concept of broad sense and narrow sense points: perishable product refers to the product itself is not easy storage or storage cost is too high to the product easy to corrosion, which is the traditional sense of the perishable product; generalized perishable goods refers to the market demand in short period products, including the quality of the product itself does not change, but the market demand is a very short cycle products, such products are mainly due to changing market consumer preferences and lead to product market short sales cycle. This study is aimed at the broad perishable products.

Technologies change rapidly, income level is gradually improved and the accelerated pace of life, the demand for the product cycle from shorter to some extent, this situation such as the technology of electronic products will be added to the perishable goods category, the category of perishable goods are expanding in the. Expand the perishable goods category, requires retailers to correct measures are put forward, to avoid the rapid loss of perishable goods value caused by the income loss to retailers. Along with the electronic commerce rapid development, reduce intermediate links of commodity circulation, hand making mistakes may allow retailers to miss the best sales period, while the retailer to quickly develop and change the sales strategy, to adapt to the change of the market; on the other hand, retailers can be analyzed by the data of consumer purchase, then based on the product the characteristics of the division, consumer groups, and then made the sale decision. After the implementation of sales decision, through market purchases to detect effect, then according to the detection structure to affect sales decision, thus to realize the dynamic pricing provides the implementation basis. Fast in the development of Internet, information characteristics of consumers for perishable products can be obtained more easily, so that consumers have more initiative in the purchase process of game. Give consumers in the process of cost, decrease with shorter perishable product life cycle. Thus for perishable products with short life cycle and its workability properties together with the consumer reservation price change has posed great challenges to manufacturers profit.

With the in-depth study, scholars found that perishable goods in advance can effectively reduce inventory risk, improve the income situation, at the same time the enterprise to return to hold more open attitude, the consumer's strategic behavior will reduce, to some extent, can enhance the enterprise income. So the study of the main point of discussion has further advancement.

You and Chen $(2007)^{[1]}$ discusses the perishable product ordering strategy and dynamic pricing problems. They divides the sales cycle into two stages, one stage is ahead of the pre-sale stage, at this stage of the sale products not allowed to return. The next stage is the normal marketing stage. In this stage the purchase of goods can enjoy the return service, so can't return in advance sales, and can lock a part number product sales, reduce the risks of enterprises. 
For perishable goods order strategy problem, Ringbom and Shy (2008) ${ }^{[2]}$ studies this problem based on the entire industry, discusses the collaborative returns within the industry, and compared the complete, return policy perfect competition and semi Alliance Service provider. Cachon and Swinney (2009b) [3] describes the consumer strategy behavior, and that the non-strategic consumers refers to the decision only to buy or out of the market, and consumers will choose when to buy strategic. Non-strategic consumers into the market, consumer surplus is greater than zero, would choose to buy; if the consumer surplus is less than zero, it will choose to wait. While consumers will compare the whole strategy of perishable goods sales cycle to obtain the consumer surplus, the final choice can obtain maximum consumer surplus time to buy the product.

In 2008, Yang Hui (2008) ${ }^{[4]}$ builds on the impact of factors, competition from earnings management angle, impact on the competitive factors in the analysis of dynamic pricing. Xiao Yongbo $(2008)^{[5]}$ further researches dynamic pricing competition under the environment, establishes a dynamic pricing model two flights. Li Gendao (2009a) ${ }^{[6]}$ studies the price decision problem for a class of perishable products demand under stochastic demand influenced by inventory and price, the importance of considering influence of inventory on demand in making decisions.

This paper mainly discusses consumer strategy behavior impact on earnings of perishable products enterprises. This paper studies two parts, one is the dynamic pricing strategy of retailers' profit behavior, and the other is the order decision on income strategy behavior.

\section{Factors Affecting the Retailer Gains}

From the economics perspective, there are two factors of product sales price and volume influence retailers' revenue. Other factors can be separately or simultaneously influence these two factors, so as to affect the retailer's revenue indirectly. To analyze the influence factors from the internal environment for retailers: quality, cost, size, price, market share, customer loyalty, the potential market. From the analysis of the external environment, the main factors are: products in the market competition, product substitutability, quality degree of product market and facing environmental laws and regulations.

In order to simplify the analysis, the retailer's fixed cost and variable cost, spread out into a single product is calculated. By considering the dynamic pricing and ordering strategy to influence the retailer's revenue, and then consider ordering strategy leads to inventory and affect the retailer's cost, final income comprehensive analysis of retailers.

If consumers demand function is $D(p)$, is a continuous function with the price of $\mathrm{P}$ real time change, and monotonically decreasing. Assume the sale period into two stages, in the sales cycle, assumes that the product sales price is $p_{1}$, in the period two sales price for $p_{2}$. Because of the existence of value passing, so suppose there are $p_{1} \geq p_{2}$. When the products are remaining, will cause a certain degree of inventory backlog, the backlog of cost is set to $\mathrm{k}$, and $p_{1} \geq p_{2} \geq k$, denotes the second stage consumers of goods probability, product inventory is $\mathrm{c}$.

\section{Effects of Dynamic Pricing on Income of Perishable Goods under Consumer Strategy Behavior}

\subsection{Effects of Dynamic Pricing in Revenue for Perishable Products}

Characteristics of retailers to sell products with the general merchandise, in accordance with the features of the consumer demand curve in economics, when the product price is lower, more consumers, and the higher the price, demand less. Consumers in the purchase of such products, there is a demand curve. Discuss the influence of dynamic pricing for perishable goods during this process; we do not consider the impact of strategies of consumers.

\subsubsection{When the Demand Function is Linear $D(p)=a-b p$}

When separate pricing, retailers get the optimal one-time pricing is $p_{0}$, and in this process, ignoring the retailers cost, only consider the benefits of retailers. Returns of retailers is

$$
\pi_{0}=p_{0}\left(a-b p_{0}\right)
$$

Bsed on derivative function available for the one-time pricing, the optimal price is

$$
p_{0}=a / 2 b
$$

Total revenue is

$$
\pi_{0}=a^{2} / 4 b
$$

When the retailers price two stage $\left(p_{1}, p_{2}\right)$, only consider the benefits, ignoring the cost of products, and $p_{1} \geq p_{2}$. The benefit formula for retailers:

$$
\pi_{1}=p_{1}\left(a-b p_{1}\right)+p_{2}\left(\left(a-b p_{2}\right)-\left(a-b p_{1}\right)\right)
$$

According to the partial derivative function of two variables, we can obtain the optimal in the two phase, the pricing combination is $(2 \mathrm{a} / 3 \mathrm{~b}, \mathrm{a} / 3 \mathrm{~b})$, finally gain is $\pi_{1}=a^{2} / 3 b$, and $\pi_{1}>\pi_{0}$. So retailers can implement the two stages pricing to gain more profit under dynamic pricing situation.

When $n \geq 2$, retailers implement multi-stage pricing $\left(p_{1}, p_{2}, \ldots, p_{n}\right)$, while the benefit formula:

$$
\begin{aligned}
\pi_{n}= & p_{1}\left(a-b p_{1}\right)+p_{2}\left(\left(a-b p_{2}\right)-\left(a-b p_{1}\right)\right)+\cdots \\
& +p_{n}\left(\left(a-b p_{n}\right)-\left(a-b p_{n-1}\right)\right)
\end{aligned}
$$

According to the partial derivative of multiple function equation, we can obtain the optimal pricing combination for multi-stage is $\left(2 a / 3 b, a / 3 b, \ldots, \quad(1 / 2)^{n-2}(a / 3 b)\right)$.

So gain formula is 


$$
\pi_{0}=2 a^{2} / 9 b+4 a^{2} / 27 b\left(1-(1 / 4)^{n-1}\right)
$$

The profit ratio to one-stage is $m=\pi_{n} / \pi_{0}$, take value of $\mathrm{n}=100$, we can get the ratio $\mathrm{m}$ in Fig 1 .

According to the analysis, if the $n=2$, multi-stage pricing revenue will higher than unchanged price income. Starting from $\mathrm{n}=9$, earnings ratio tends to the maximum 1.4815 . Dynamic pricing gives retailers more revenue than the price does not change.

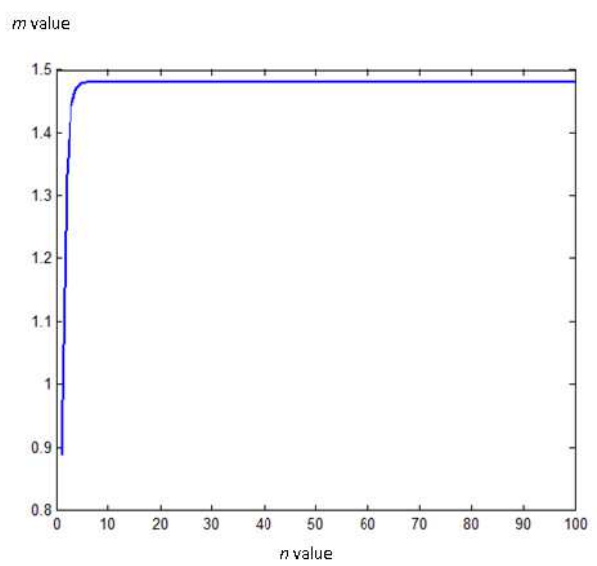

Figure 1. The ratio of $m$ trend under condition one.

3.1.2. When the Demand Function Curve Is $D(p)=a e^{-b p}$

Similarly, when separate pricing retailers get the optimal one-time pricing is $p_{0}$, and in this process, ignoring the retailers cost, only consider the benefits of retailers. Returns of retailers is

$$
\begin{gathered}
\pi_{0}=p_{0} a e^{-b p_{0}} \\
\left(\frac{1}{b}+\frac{1}{b}\left(1-e^{-1}\right)+\frac{1}{b}\left(1-e^{-\left(1-\frac{1}{e}\right)}\right), \frac{1}{b}\right. \\
\frac{1}{b}\left(1-e^{-\left(1-\frac{1}{e}\right)}\right)+\frac{1}{b}\left(1-e^{-\left(1-e^{-\left(1-\frac{1}{e}\right)}\right)}\right), \\
\left.\frac{1}{b}\left(1-e^{-\left(1-e^{-\left(1-\frac{1}{e}\right)}\right)}\right)\right)
\end{gathered}
$$$$
\left(\frac{1}{b}+\frac{1}{b}\left(1-e^{-1}\right)+\frac{1}{b}\left(1-e^{-\left(1-\frac{1}{e}\right)}\right), \frac{1}{b}\left(1-e^{-1}\right)+\frac{1}{b}\left(1-e^{-\left(1-\frac{1}{e}\right)}\right)+\frac{1}{b}\left(1-e^{-\left(1-e^{-\left(1-\frac{1}{e}\right)}\right)}\right),\right.
$$

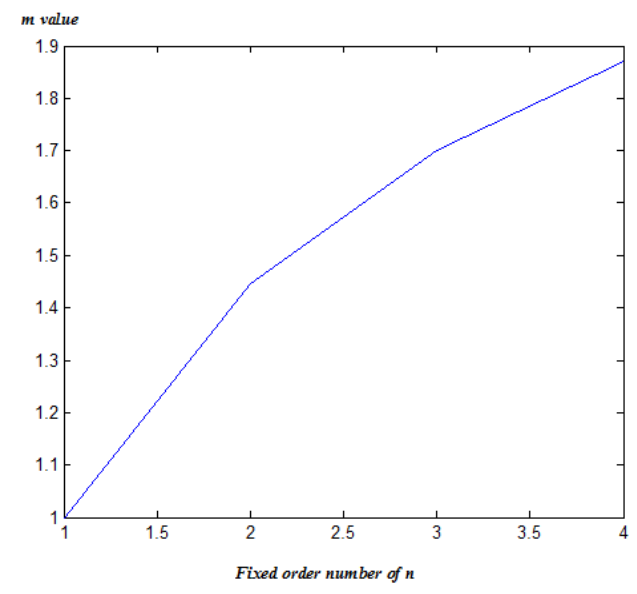

Figure 2. The ratio of $m$ trend under condition two. increasing.

\subsection{The Influence of Dynamic Pricing on Income Considering Consumer Strategy Behavior}

Based on derivative function available for the one-time pricing, the optimal price is $p_{0}=1 / b$, total revenue is

$$
\pi_{0}=a / e^{b}
$$

When the retailers price two stage $\left(p_{1}, p_{2}\right)$, only consider the benefits, ignoring the cost of products, and $p_{1} \geq p_{2}$. The benefit formula for retailers:

$$
\pi_{1}=p_{1} a e^{-b p_{1}}+p_{2}\left(a e^{-b p_{2}}-a e^{-b p_{1}}\right)
$$

According to the partial derivative function of two variables, we can obtain the optimal in the two phase, the pricing combination is

$$
((1 / b)(2-1 / e),(1 / b)(1-1 / e))
$$

Finally gain is

$$
\pi_{1}=a e^{-(1-1 / e)} / b
$$

Where $\pi_{1}>\pi_{0}$. So retailers can implement the two stages pricing to gain more profit under dynamic pricing situation.

When $n \geq 2$, retailers implement multi-stage pricing $\left(p_{1}, p_{2}, \ldots, p_{n}\right)$, while the benefit formula:

$$
\pi_{n}=p_{1} a e^{-b p_{1}}+p_{2}\left(a e^{-b p_{2}}-a e^{-b p_{1}}\right)+\cdots+p_{n}\left(a e^{-b p_{n}}-a e^{-b p_{n-1}}\right)
$$

According to the partial derivative of multiple function equation, we can obtain the optimal pricing combination for multi-stage. Because the expression is complicated, we will set the number of dynamic pricing is four, then can obtain the price of each stage are

The profit ratio to one-stage is $m=\pi_{n} / \pi_{0}$, take value of $n=4$, we can get the ratio $m$ trend in Fig 2 . Under the assumption of the condition, with the increase of the number of $\mathrm{n}, \mathrm{m}$ value is also in constant increase, indicate that with the increase in the number of retailers pricing, revenue is

For convenience of the analysis, dynamic pricing with retailers in two stage pricing $\left(p_{1}, p_{2}\right)$, the customer has certain strategic in the first stage, suppose that in first stage, non strategic consumer's proportion is $r$, the proportion of strategy consumers is 1-r. In the course of the discussion, we do not consider the impact of inventory cost still. The first 
stage of commodity price is $\mathrm{p}_{1}$, the second phase of the price is $\mathrm{p}_{2}$, when the demand function is $D(p)$, can get the benefit formula for retailers:

$$
\pi=r p_{1} D\left(p_{1}\right)+p_{2}\left[(1-r) D\left(p_{1}\right)+\left(D\left(p_{2}\right)-D\left(p_{1}\right)\right)\right]
$$

Set the demand function is $D(p)=a e^{-b p}$,

$$
\pi=r p_{1} a e^{-b p_{1}}+p_{2}\left[(1-\mathrm{r}) a e^{-b p_{1}}+\left(a e^{-b p_{2}}-a e^{-b p_{1}}\right)\right]
$$

According to the partial derivative of two variables function, we can obtain that,

$$
\begin{gathered}
\frac{\partial \pi\left(p_{1}, p_{2}\right)}{\partial p_{1}}=r a e^{-b p_{1}}\left(1-b p_{1}+b p_{2}\right)=0 \\
\frac{\partial \pi\left(p_{1}, p_{2}\right)}{\partial p_{2}}=a e^{-b p_{2}}\left(1-b p_{2}-r e^{-b\left(p_{1}-p_{2}\right)}\right)=0
\end{gathered}
$$

We can get

$$
\begin{aligned}
& p_{1}=\frac{1}{b}\left(2-\frac{r}{e}\right) \\
& p_{2}=\frac{1}{b}\left(1-\frac{r}{e}\right)
\end{aligned}
$$

The profit is

$$
\pi=\frac{a}{b} e^{\frac{r}{e}-1}
$$

When the retailer does not consider consumer strategy behavior, will be the optimal $\left(p_{1}, p_{2}\right)$, as $(1 / \mathrm{b}(2-1 / \mathrm{e}), 1 / \mathrm{b}$ (1-1/e)), into the $\pi$ formula, finally obtained income:

$$
\pi_{1}=\frac{a}{b} e^{-\left(2-\frac{1}{e}\right)}(r+e-1)
$$

Let $m^{\prime}=\pi / \pi_{1}$, we can get into the consumer strategy behavior in the retailer gains and does not consider the consumer strategy behavior gains than the $m^{\prime}$.Fig 3 is the relationship of earnings ratio $\mathrm{m}^{\prime}$ with the ratio $\mathrm{r}$.

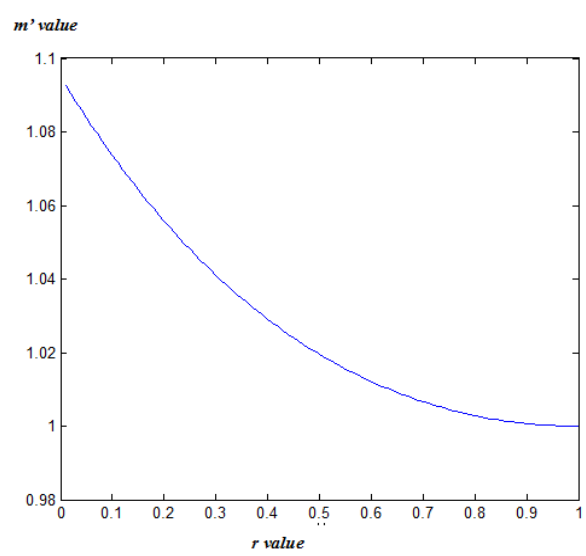

Figure 3. The relationship of earnings ratio $m^{\prime}$ with the ratio $r$.
According to the ratio of the trend in the graph, we can see that, when the consumer strategy scale (1-r) is large that the retailer does not consider the consumer's strategic behavior is not wise, that would loss part of the income. At the same time, along with the gradually reduce the proportion of strategy consumers, the retailers' profit under considering consumer strategy behavior or not are gradually be the same.

\section{Conclusion}

This paper mainly discusses consumer strategy behavior impact on earnings of enterprises perishable products. It mainly considers from the aspects of income and cost, analyzes retailers from selling products, easy to affect the factor income, and then analyzes other factors how to influence the two factors, thus indirectly affect the retailer's cost. And it focuses on the two parts, one is the effect of dynamic pricing strategy behavior of retailers' profit, the other is ordering decision to return strategy behavior.

The pricing factors will affect the sale of the product prices, thus affecting the income of the retailers. Retailers need to constantly change price, price discrimination, to get more consumer surplus at the same time, through the influence of product sales, increase income. In the process of dynamic pricing, as prices change, consumers buy goods in different stages of the different effects, at a time when consumers are strategic behavior, waiting for a chance to buy, so that they get the maximum consumer surplus. In this case, it discusses return of retailers under the condition of considering consumer strategy behavior and do not consider the consumer strategy behavior, and prove that in the presence of consumer strategy behavior conditions, retailers for this kind of behavior cannot be ignored.

Retailers ordering strategies affect retailers last remaining inventory cost and shortage cost. Influencing factors on the two aspects, retailers need to find a suitable quantity. This paper firstly analyzes the effect of order decision on retailers' profit, and then discusses the thinking strategy behavior and do not consider the consumer strategy behavior, affect the ordering decisions on income. The article concludes that in the presence of the consumer strategy behavior, retailers in order cannot ignore the strategy behavior of consumers.

\section{Acknowledgments}

The study is supported by Beijing philosophy and social sciences planning project "Statistical measure and quantitative studies on the development of green logistics in Beijing "(13JGC078), Beijing Key Laboratory of Intelligent Logistics System, Beijing Wuzi University (BZ0211), and modern logistics information and control technology of Beijing Wuzi University research base-technology innovation platform(PXM2012_014214_000067). 


\section{References}

[1] P. S.You, T. C. Chen, "Dynamic pricing of seasonal goods with spot and forward purchase demands," Computers and Mathematics with Applications, vol54,2007, pp. 490-498.

[2] S. Ringbom, O. Shy, "Refunds and collusion in service industries," Journal of Economics and Business, vol60, 2008, pp. 502-516.

[3] G. P. Cachon, R. Swinney, "Purchasing, pricing, and quick response in the presence of strategic consumers," Management Science, vol55, 2009a, pp.497-511.

[4] H. Yang, J. Zhou, "Mechanism analysis of competitive pricing decision of revenue management," Journal of Nanjing University of Science and Technology, vol21,2008, pp.50-54.

[5] Y. B. Xiao, J. Chen, X.L. Liu, "Joint dynamic pricing for two parallel flights based on passenger choice behavior," Systems engineering theory \& Practice, vol1,2008, pp.46-55.

[6] G. D. Li, Z. K. Xiong, J. J. Nie, "Dynamic pricing for perishable products with inventory and price sensitive demand," Journal of Systems \& Management, vol18, 2009, pp. 402-409. 